\title{
Spatiotemporal dynamics of the processing of spoken inflected and derived words: a combined EEG and MEG study
}

\section{Alina Leminen ${ }^{1}$, Miika Leminen ${ }^{1,2}$, Minna Lehtonen ${ }^{1,3,4}$, Päivi Nevalainen ${ }^{5}$, Sari Ylinen ${ }^{1}$, Lilli Kimppa $^{1}$, Christian Sannemann ${ }^{1}$, Jyrki P. Mäkelä ${ }^{5}$ and Teija Kujala'}

\author{
1 Cognitive Brain Research Unit, Cognitive Science, Institute of Behavioural Sciences, University of Helsinki, Helsinki, Finland \\ 2 Finnish Centre of Excellence in Interdisciplinary Music Research, Finland \\ 3 Department of Psychology and Logopedics, Åbo Akademi University, Turku, Finland \\ 4 Low Temperature Laboratory, Aalto University School of Science and Technology, Espoo, Finland \\ 5 BioMag Laboratory, HUSLAB, Hospital District of Helsinki and Uusimaa, Helsinki, Finland
}

\section{Edited by:}

Hans-Jochen Heinze, University of Magdeburg, Germany

\section{Reviewed by:}

Juliana Yordanova, Bulgarian Academy of Sciences, Bulgaria

Mirjana Bozic, University of Cambridge, UK

\section{${ }^{*}$ Correspondence:}

Alina Leminen, Cognitive Brain Research Unit, Cognitive Science, Institute of Behavioural Sciences, University of Helsinki,

Siltavuorenpenger 1 B, PO Box 9 , Helsinki 00014, Finland.

e-mail: alina.leminen@helsinki.fi
The spatiotemporal dynamics of the neural processing of spoken morphologically complex words are still an open issue. In the current study, we investigated the time course and neural sources of spoken inflected and derived words using simultaneously recorded electroencephalography (EEG) and magnetoencephalography (MEG) responses. Ten participants (native speakers) listened to inflected, derived, and monomorphemic Finnish words and judged their acceptability. EEG and MEG responses were time-locked to both the stimulus onset and the critical point (suffix onset for complex words, uniqueness point for monomorphemic words). The ERP results showed that inflected words elicited a larger left-lateralized negativity than derived and monomorphemic words approximately $200 \mathrm{~ms}$ after the critical point. Source modeling of MEG responses showed one bilateral source in the superior temporal area 100 ms after the critical point, with derived words eliciting stronger source amplitudes than inflected and monomorphemic words in the right hemisphere. Source modeling also showed two sources in the temporal cortex approximately $200 \mathrm{~ms}$ after the critical point. There, inflected words showed a more systematic pattern in source locations and elicited temporally distinct source activity in comparison to the derived word condition. The current results provide electrophysiological evidence for at least partially distinct cortical processing of spoken inflected and derived words. In general, the results support models of morphological processing stating that during the recognition of inflected words, the constituent morphemes are accessed separately. With regard to derived words, stem and suffix morphemes might be at least initially activated along with the whole word representation.

Keywords: auditory, morphology, MEG, infected, derived, ERP, lexicon

\section{INTRODUCTION}

One of the controversies in psycholinguistics and cognitive neuroscience of language has been the question of how morphologically complex words such as "work $+s$ " and "work + er" are accessed and represented in the mental lexicon: as full entities or via constituent morphemes? Moreover, there is no consensus on the neural correlates of these processes. Furthermore, most psycholinguistic studies on morphological processing have used visual stimuli, whereas evidence on neural processing of spoken complex words is scarce. The current study investigates the neural processing of spoken inflected and derived words. Inflectional affixes typically specify syntactic relations, whereas derivational affixes have a lexical-semantic function (e.g., Scalise, 1988; Badecker and Caramazza, 1989; Anderson, 1992; Stump, 1998; but see, e.g., Bybee, 1985). That is, derivational affixes attach to a stem to form a new lexeme (e.g. "work" + "er" = "worker"), whereas inflectional affixes attach to a stem to convey grammatical information (e.g., "work" + "s" = "works"). In addition, derivational affixes may change the syntactic category of their stem [e.g., "happy" (adjective) $\rightarrow$ "happiness" (noun)], whereas inflectional affixes usually do not ["boy" (noun) $\rightarrow$ "boys" (noun)]. Inflectional affixes are also usually more productive than derivational affixes and inflections tend to be semantically more transparent than derivations (Scalise, 1988; Stump, 1998). Nevertheless, in psycholinguistics and cognitive neuroscience of language controversy still exists on whether derived and inflected words are processed and represented in a similar or different manner, and especially whether their processing differs at the neural level.

Some psycholinguistic models suggest that all morphologically complex words are represented and processed in their full form (Butterworth, 1983), while others claim that each complex word is decomposed into its constituent morphemes (Taft and Forster, 1975; Taft, 1979; Stockall and Marantz, 2006; Rastle and Davis, 2008). The prelexical decomposition view assumes that inflected and derived words alike would first be segmented by a semantically blind parser into their stems ("work") and affixes ("-s" or "-er"). This parsing process would operate early and automatically upon all potential (regularly) inflected and derived forms and would be triggered by the surface formal properties of these words (for recent reviews, see Marslen-Wilson and Tyler, 2007; Rastle and Davis, 2008). Several models also propose that both decompositional and full-form processing are used during complex word recognition (e.g., Caramazza 
et al., 1988; Frauenfelder and Schreuder, 1992; Niemi et al., 1994; Schreuder and Baayen, 1995), with factors such as word frequency, suffix productivity, morphological family size, semantic transparency, regularity, and suffix allomorphy, etc. affecting the processing "route" used (Caramazza et al., 1988; Pinker, 1991; Frauenfelder and Schreuder, 1992; Schreuder and Baayen, 1995; McQueen and Cutler, 1998; Clahsen et al., 2003). Moreover, some dual-route models explicitly suggest decompositional processing of inflected words and full-form processing for derived words (Niemi et al., 1994).

In a morphologically productive language such as Finnish, each noun can have up to 140 different paradigmatic inflectional forms and each verb may have over 200 inflectional forms (clitics excluded; Hakulinen et al., 2004). In Finnish, most inflected words (except for the most frequent ones) show a morphological processing cost, i.e., higher error rates and longer reaction times than monomorphemic words (Laine et al., 1995; Soveri et al., 2007), unlike most derived Finnish words (Bertram et al., 1999; Vannest et al., 2002).

The time course of the processing of inflected words has been reported in a number of ERP studies, many of which used a violation paradigm or priming, showing N400 and/or left anterior negativity (LAN) effects at around 300-500 ms after stimulus onset (Penke et al., 1997; Weyerts et al., 1997; Gross et al., 1998b; Münte et al., 1999; Rodriguez-Fornells et al., 2001; Allen et al., 2003; Morris and Holcomb, 2005; Linares et al., 2006; Lück et al., 2006; Lehtonen et al., 2007; Newman et al., 2007; Leinonen et al., 2008, 2009). The LAN effect has been suggested to reflect difficulties with integrating a regularly inflected word into its syntactic context, processes related to morphological structure building (e.g., Penke et al., 1997; Rodriguez-Fornells et al., 2001; Morris and Holcomb, 2005), as well as mismatch of the presented stimuli with stored representations (Krott et al., 2006). A few studies employing a direct contrast between morphologically complex and simple words have shown larger N400 effects during the recognition of Finnish inflected single words as compared to matched monomorphemic words (Lehtonen et al., 2007; Leinonen et al., 2009). Similarly, with magnetoencephalography (MEG), Vartiainen et al. (2009a) observed stronger and longer-lasting $\mathrm{N} 400 \mathrm{~m}$ responses during reading of inflected words as compared to monomorphemic words. These larger N400 effects were interpreted to reflect lexical-semantic access and integration of morphemic constituents of the (correctly) inflected words.

In contrast to inflections, ERP studies on derived word processing are more scarce. Two recent ERP studies reported a LAN for derivational violations, suggested to reflect structural difficulties with processing anomalous derived stimuli (Palmovic and Maricic, 2008; Bölte et al., 2009a). On the other hand, the processing of derivationally violated stimuli has also elicited N400/N400m effects, which have been proposed to reflect lexical anomaly detection (Janssen et al., 2006; Leinonen et al., 2008) or difficulties with semantic integration of the morphemes (Bölte et al., 2009b). A recent MEG study reported larger M170 responses for derived than for simple words, taken to reflect an early form-based decomposition of complex words (Zweig and Pylkkänen, 2008). Using spoken derived stimuli, a recent ERP study reported a larger wide-spread negativity for illegal derived pseudowords as compared to existing derived words and legal derived pseudowords $\sim 300 \mathrm{~ms}$ after suffix onset (Leminen et al., 2010). This larger negativity (resembling the N400) was interpreted as reflecting failed lexical-semantic licensing and integration of the morpheme constituents.
Hemodynamic studies contrasting the recognition of regular vs. irregular inflection have reported stronger activation of the left inferior frontal gyrus (LIFG) as well as of left temporal regions for regular words (e.g., Tyler et al., 2005). Activations in LIFG have been interpreted to reflect morphophonological segmentation and grammatical analysis of regularly inflected words (Tyler et al., 2005), whereas activations in the left temporal regions have been suggested to reflect access to semantic representations of the stem and affix (Tyler et al., 2005). Furthermore, in a PET study, Laine et al. (1999) observed stronger activation in LIFG for memory encoding of Finnish spoken inflected words than monomorphemic words. More recently, Lehtonen et al. (2006) reported that recognition of Finnish inflected nouns elicited stronger activation in LIFG and in the left posterior superior temporal sulcus as compared to monomorphemic words. The LIFG activation was suggested to denote integration of the stem and the affix (Lehtonen et al., 2006). Similar to the findings on inflected words, the processing of derived words evokes activity in the left inferior frontal areas (Vannest et al., 2005; Bozic et al., 2007; Meinzer et al., 2009), but also in the basal ganglia (Vannest et al., 2005), the left occipito-temporal areas (Gold and Rastle, 2007), and bilateral temporo-occipital and right parietal areas (Meinzer et al., 2009; for a recent review, see Bozic and Marslen-Wilson, 2010).Localization of morphological processing with MEG has revealed stronger left temporal cortex activation associated with the recognition of correctly inflected vs. monomorphemic (Vartiainen et al., 2009a) and incorrectly vs. correctly derived (Bölte et al., 2009b) stimuli.

Here, we investigated the spatiotemporal dynamics of morphological processing of spoken Finnish inflected and derived single words. We aimed to determine with MEG the neural source loci activated by spoken inflected and derived words, an issue with very little investigation so far. The simultaneous registration of MEG and ERP data allowed us to directly compare our results with previous ERP findings. Furthermore, some models of morphological processing predict differences for the processing of inflected and derived words (e.g., Niemi et al., 1994). While behavioral, eye-tracking, and neuropsychological patient evidence has demonstrated a processing cost for Finnish inflected nouns in comparison to monomorphemic nouns, derived words have typically not shown such a cost (e.g., Niemi et al., 1994; Hyönä et al., 1995; Bertram et al., 1999; Vannest et al., 2002). This has been taken as evidence for decomposition for inflected words but full-form recognition for derived words. Recent ERP evidence testing the recognition of inflected and derived stimuli directly has also shown that derived and inflected stimuli presented visually in a sentence context show a distinct pattern of responses (Leinonen et al., 2008). These results suggest that inflection and derivation might be governed by at least partially distinct neural mechanisms, supporting some dualroute models of morphological processing (e.g., Niemi et al., 1994). During listening, however, the temporal unfolding of a complex word may give a head-start for accessing the stem separately from the suffix. Thus, we were interested in seeing whether there would be any differences between the (correctly) inflectional and derivational processing in the auditory modality as well.

Based on previous findings (Lehtonen et al., 2007; Leinonen et al., 2009; Vartiainen et al., 2009a), inflected words were expected to undergo morphological decomposition during their processing, which may be reflected in larger electrophysiological responses (such as $\mathrm{N} 400 / \mathrm{N} 400 \mathrm{~m}$ ) than those to monomorphemic words. We 
were interested in finding out whether the recognition of (correctly) derived words would involve retrieving the derived words in their full form (Bertram et al., 1999; Vannest et al., 2002), which might be reflected in the similar electrophysiological responses for derived and monomorphemic words, and smaller responses for derived than for inflected words. On the other hand, the morpheme-based processing of derived words might be indexed by, e.g., larger N400/N400m responses as compared to monomorphemic words and similar electrophysiological responses for inflected and derived words. Based on MEG studies with spoken stimuli (e.g., Helenius et al., 2002; Shtyrov et al., 2003; Uusvuori et al., 2008; Pulvermüller and Shtyrov, 2009; Pulvermüller et al., 2009; Vartiainen et al., 2009b), the left superior temporal cortex is likely to be activated for all stimuli, but possibly more strongly for the morpheme-based processing of complex words as compared to monomorphemic words (Vartiainen et al., 2009a).

Additionally, most previous studies on auditory morphological processing have not addressed the problem of a large amount of stimuli resulting in timing differences in affix-related processing for different stimuli. The variance in the onset of the critical information (e.g., suffix onset or recognition point) may reduce or abolish the responses to this information, particularly if they are short-lived and focal (Pulvermüller et al., 2009; Leminen et al., 2010). Since it is essential to relate latencies to the point in time when the sensory information crucial for morphological processing and/or word recognition is available (Pulvermüller et al., 2009; Leminen et al., 2010), we time-locked the responses precisely to the onset of the critical information for each word individually (rather than to the average onset).

\section{MATERIALS AND METHODS PARTICIPANTS AND ETHICAL CONSIDERATIONS}

Ten healthy right-handed adults (six males) participated in the present study (age range 18-34 years, mean 26 years). All participants were native speakers of Finnish. None of the participants reported any hearing defects, linguistic dysfunctions, or neurological disorders. The participants gave their written informed consent to participate in the experiments. The experiments were performed in accordance with the Declaration of Helsinki. Ethical permission for the experiment was issued by the Research Ethics Committee of the Helsinki University Central Hospital.

\section{STIMULI}

Three 75 item word lists and three 75 item pseudoword filler lists were compiled for the acceptability judgment task. One word list consisted of monomorphemic Finnish words (e.g., "morsian"/“bride"), another of case-inflected words (including genitive, partitive, essive, and different locatives, e.g., "talo + ssa"/"in a house"), and third consisting of derived words (including collective, possessive, and caritive suffixes, e.g. "karva + ton"/“hairless"). These inflectional and derivational suffixes have been previously used in several studies with Finnish stimuli (e.g., Laine, 1996; Bertram et al., 1999; Vannest et al., 2002; Lehtonen and Laine, 2003; Lehtonen et al., 2007; Leinonen et al., 2009). All suffixes were attached to nominal stems. In each inflected or derived word, the base morpheme was different, and there were no repeated stems. Most of the stems (90\%) were morphophonologically transparent, i.e., they did not undergo consonant gradation during insertion of a derivational or inflectional ending. The pseudowords consisted of items that had an existent noun stem and an existing suffix but their combination was morphophonologically illegal, due to a failed consonant gradation (e.g. , ${ }^{\star} k y l p y+n,{ }^{*}$ lintu + sto; the correct form "kylvyn"/“linnusto"). In addition to the morphologically complex pseudowords, we used 75 monomorphemic pseudowords that complied with the phonotactic rules of Finnish (e.g., vorsilo). The pseudowords were formed by changing one to three letters from existing monomorphemic Finnish words.

The derived words and inflectional stems were selected using the Finnish corpus (approximately 109 million tokens) composed by the Research Institute for the Languages of Finland, the Finnish IT center for science and the Department of General Linguistics, University of Helsinki. Mean log base frequencies for the inflected words were 0.98 per million, for derived items 1.47 per million, and for monomorphemic words 0.12 per million. The log surface frequencies for the inflected, derived, and monomorphemic words were $-0.5,-0.52$, and 0.8 per million, respectively ${ }^{1}$.

Stimuli were spoken at a normal rate in a randomized order by a female native speaker of Finnish and recorded directly onto a computer hard-drive, using a 44.1-kHz sampling frequency and 16-bit quantization. Mean stimulus duration for inflected words was $727 \mathrm{~ms}(\mathrm{SD}=81)$, for derived words $783 \mathrm{~ms}(\mathrm{SD}=72)$, and for monomorphemic words it was $741 \mathrm{~ms}(\mathrm{SD}=91)$. Due to variations in the duration of the base morpheme, we were not able to match the whole word durations (all $p$-values $>0.05$ ). However, time-locking of our responses to the precise onset of the critical point ensured that the overall duration of the stimulus was not relevant, because the onsets of the suffixes were matched.

A temporal display of each auditory stimulus was used to establish the time point at which the critical point was presented. For each affixed word, the time point of the suffix onset in each auditory file was marked with a trigger code for the purpose of time-locking electrophysiological responses to critical points. For monomorphemic words, in which there are no suffixes, we set a trigger at the uniqueness point (UP). The UP (i.e., the phoneme at which a word deviates from all words that share the same phonemes up to and including the phoneme preceding the UP) was determined by a corpus search. In all words the meaning of the base morpheme (and in the case of monomorphemic words, the whole word) was accessed at the critical point. The mean suffix onset for the inflected words took place at $521 \mathrm{~ms}(\mathrm{SD}=92)$ and $492 \mathrm{~ms}(\mathrm{SD}=72)$ for the derived words. For monomorphemic words, the mean onset of the UP was $526 \mathrm{~ms}(\mathrm{SD}=76)$. The mean fundamental frequency (F0) for the inflected, derived, and monomorphemic words was

${ }^{1}$ Due to the limited amount of available derived stimuli, we were not able to match fully all the conditions with regard to frequency. While the derived and inflected word groups were well matched for $\log$ surface frequency $(p=0.356)$, the monomorphemic words were more frequent than inflected and derived words $(p<0.05)$. Yet, this difference is unlikely to be the source of the observed effects: it is likely that the higher frequency would only have decreased the observed differences, and assumedly in the same way for derived and inflected words. The log base frequency values differed across conditions (all $p$-values $<0.05$ ). To exclude the possibility that the differences in the ERP responses could be due to frequency differences, we conducted separate ANOVA analyses 300-500 ms after the stimulus onset and -200 to $0 \mathrm{~ms}$ before the critical point, the time windows when stem access took place. None of these analyses showed significant effects within each critical time-window (for a similar approach, see Janssen et al., 2006). The results of these tests thus clearly show that there were no significant differences in the ERP amplitude during the base morpheme access, and that the possible base frequency differences did not have notable effects on the ERP responses. 
$206 \mathrm{~Hz}(\mathrm{SD}=8), 204 \mathrm{~Hz}(\mathrm{SD}=13)$, and $206 \mathrm{~Hz}(\mathrm{SD}=6)$, (no differences between the conditions, all $p$-values $>0.05)$. The stimuli were also matched by their sound energy [inflected, derived, and monomorphemic words-75 $\mathrm{dB}(\mathrm{SD}=11), 74 \mathrm{~dB}(\mathrm{SD}=2)$, and $74 \mathrm{~dB}(\mathrm{SD}=2)$, no differences between the conditions, all $p$-values $>0.05]$. Additionally, we verified that the word endings after the critical point in different conditions did not differ acoustically on the electrophysiological level (N1 and P2 amplitudes). In this control study, naive participants (not included in the actual study) listened passively only to target endings separately from the base morpheme. The results of this control study showed no significant differences between inflectional and derivational suffixes in the magnitude of the $\mathrm{N} 1$ or $\mathrm{P} 2$ components (all $p$-values $>0.05$ ). These results verify that the possible differences in morphological processing should not be due to acoustic differences between the conditions.

\section{PROCEDURE}

The experiment consisted of altogether 450 trials, 75 trials per stimulus condition. The stimulus presentation was divided into three blocks and the order of the blocks was randomized for each subject. The stimuli within each block were presented in a randomized order. The stimuli were presented binaurally through plastic tubes at a comfortable sound level. The stimulus presentation was commanded by a script written in Presentation 12.2 (Neurobehavioral Systems, Albany, NY, USA). The participants were asked to indicate as accurately as possible whether the items were acceptable Finnish words. The responses were collected using a silent optical switch in which the subject's finger interrupted a modulated light beam. The participants lifted their right index finger if the word was acceptable and middle finger if the word was unacceptable, yielding error rates as the dependent variable. The inter-trial interval was $1500 \mathrm{~ms}$. To avoid eye movements, the participants were instructed to look at the fixation point in the middle of the screen. The total duration of the experiment was approximately $1.5 \mathrm{~h}$ including participant preparation.

\section{DATA ACQUISITION}

The recordings were performed in a shielded room (ETS-Lindgren Euroshield, Eura, Finland) with a Vectorview ${ }^{\mathrm{TM}}$ whole head MEG system (ElektaNeuromag ${ }^{\circledast}$,Elekta Oy, Helsinki, Finland). The dewar was in the seated position. The 306-channel helmet-shaped system consists of 102 sensor elements each comprising two orthogonal planar gradiometers and one magnetometer. The planar gradiometers show strongest responses right above the source, whereas magnetometers give two response maxima with opposite polarities on opposite sides of the cortical source. The electroencephalography (EEG) was recorded with a 64-channel electrode cap using an amplifier designed and built for simultaneous EEG and MEG recordings (Virtanen et al., 1996). Additional electrodes were placed on the left and right mastoids. Horizontal EOG was monitored with electrodes placed at the temples and the vertical EOG with electrodes attached above and below the left eye. The reference electrode was attached to the nose and ground electrode to the cheek. The head position inside the recording device was determined by activating four indicator coils in relation to the cardinal points of the head (nasion, left and right preaurical points), which were identified prior to the experiment with an Isotrak 3D-digitizer (Polhemus, Colchester, VT, USA). The EEG and MEG signals were band-pass filtered between 0.1 and $200 \mathrm{~Hz}$ and digitized at $600 \mathrm{~Hz}$.

\section{DATA ANALYSIS}

The continuous MEG raw data were pre-processed offline using a spatiotemporal signal space separation (tSSS) method of the MaxFilter $^{\mathrm{TM}}$ software (ElektaNeuromag ${ }^{\circledR}$, Elekta Oy, Helsinki, Finland), to minimize the effects of external interference (e.g., line frequency noise) and artifacts produced by nearby sources (e.g., the heart and dental braces; Taulu and Simola, 2006). tSSS was performed in a 4-s time window (thus, suppressing frequencies below $0.25 \mathrm{~Hz}$ ) with the default correlation limit of 0.98 . Thereafter, the EEG and MEG data were processed with BESA Research 5.3 Software (BESA GmbH, Munich, Germany). The data were lowpass filtered at $45 \mathrm{~Hz}$. The EEG data were referenced offline to the average mastoids. Any channels with technical malfunction were replaced by interpolating the data of the surrounding electrode sites (Perrin et al., 1989; Bendixen et al., 2008). The data were further processed by an automatic eye-blink correction using principal component analysis (PCA; Ille et al., 2002) and other remaining artifacts were removed automatically using $\pm 100 \mu \mathrm{V}$ rejection level for EEG data as well as $1200 \mathrm{ft} / \mathrm{cm}$ and $2000 \mathrm{ft}$ rejection level for gradiometers and magnetometers, respectively. Thereafter the EEG and MEG responses were epoched (time-locked in separate averages to both stimulus onset and critical point) and baseline corrected. Data time-locked to the stimulus onset were epoched using a time window of -200 to $1200 \mathrm{~ms}$ with a baseline correction of -200 to $0 \mathrm{~ms}$, whereas data time-locked to the critical point were epoched using a time window of -200 to $700 \mathrm{~ms}$ and baseline correction of -200 to $0 \mathrm{~ms}$ before the critical point.

\section{SOURCE MODELING}

The grand average magnetic flux pattern was first examined in order to obtain an overview of the distribution of electromagnetic energy around the head (Harris et al., 2008; see Figure 1). Visual inspection of the overall magnetic flux at $\sim 0-150 \mathrm{~ms}$ revealed similar stable flux patterns across conditions. However, at $\sim 150 \mathrm{~ms}$ after the critical point the magnetic flux pattern changed and stabilized. Grand average magnetic flux distribution thus suggested two fit intervals. Additionally, a PCA was applied on the grand average MEG data. PCA demonstrated that the majority of the total variance $(95.3 \%)$ could be optimally explained by two principal components in all stimulus conditions. This implied that the flux pattern could be modeled with the maximum of two mono- or bilateral source patterns.

Source locations of the MEG data were initially determined using L1 norm minimum current estimates (MCE) in order to acquire an overview of the spatial distribution of the activity and to compare it with sources obtained with equivalent current dipole (ECD) modeling. After the distributed source estimation, cortical sources of the magnetic fields were modeled as ECDs for the activity after the critical point. All 204 gradiometers were used in dipole modeling. Although this method may increase between-subject variance in location, it removes any subjectivity associated with sensor selection (Pylkkänen et al., 2006).

The dipoles were fitted in two time-windows (80-120 and 170$210 \mathrm{~ms}$ after the critical point) based on the magnetic flux distribution. Goodness of fit ( $\mathrm{GoF}$ ) values larger than $80 \%$ were defined as indicating adequate multiple dipole models (Hansen et al., 2010). In the 80-120 ms time-window, the grand average magnetic field activity was best explained by one bilateral source [henceforth, Source pattern 1; mean $(\mathrm{GoF}) 84 \%(\mathrm{SD}=6)$, no differences between conditions 


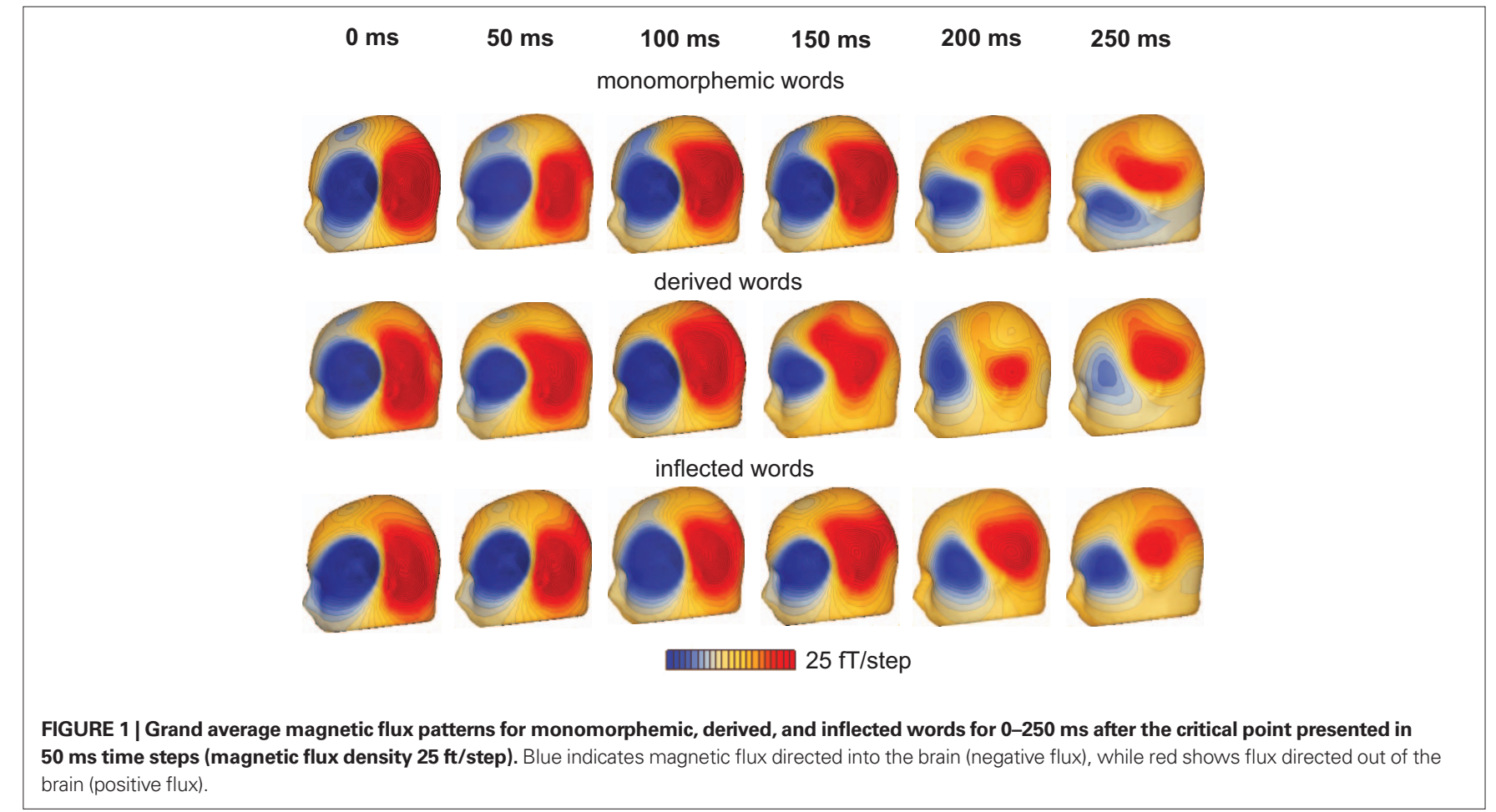

$(F<2)]$. In the 170-210 ms time window, the field pattern was poorly explained by Source pattern 1 only $(\mathrm{GoF}<80 \%)$. Thus, Source pattern 1 explained only part of the data in the 170-210 ms time window and a second source was required to account for yet unexplained activity. Thereafter a second bilateral source (henceforth, Source pattern 2) was added to the model and with two bilateral sources, GoF reached $80 \%$ [mean GoF: $81 \%(S D=7)$, no differences between conditions $(F<1)]$.

The model with two bilateral dipoles (four dipoles altogether) was then applied to the individual data for the two time windows and three stimulus conditions. The individual dipoles with a poorer GoF $(<80 \%)$ were not included in the final analyses. Overall, the sources of eight participants were included in the final solution for Source pattern 1. For Source pattern 2, the left hemisphere sources of seven participants and the right hemisphere sources of six participants were included in the model. Dipole locations were expressed in the Cartesian coordinate system: the $X$-axis runs from left to right, the $Y$-axis from posterior to anterior, and the $Z$-axis from inferior to superior. In order to assess the differences between dipole locations between conditions, Euclidean distance (ED) was calculated for the Cartesian coordinates of these dipole locations. The location and strength of Source patterns 1 and 2 were assessed for each subject.

In order to obtain an overview of the source activity of the EEG data and to compare it with MEG source modeling, we calculated grand average LORETA on the ERP responses in the 190-230 ms after the critical point using the BESA Research 5.3 software.

\section{STATISTICAL ANALYSES Behavioral data}

Error rate data (the mean percentage of incorrect responses) and reaction time data measured from the critical point were analyzed with two separate one-way repeated measures analyses of vari- ance (ANOVA) for the within-subject factor Condition (monomorphemic, derived, inflected) $)^{2}$. Post hoc tests were performed using the least significant differences (LSD) test. All $p$-values were Greenhouse-Geisser corrected for non-sphericity when appropriate. The significance was set to 0.05 .

\section{ERP data}

The ERP data were analyzed by means of repeated measures ANOVAs. The mean amplitudes for the stimulus onset timelocked data were calculated in the 700-780 ms time window. This time-window was selected on the basis of visual inspection, as there inflected words showed a more negative deflection as compared to other stimuli. The long latency of this time-window can be explained by the fact that the durations of the stimuli were relatively long (on average, over $750 \mathrm{~ms}$, see Stimuli) and the average onsets of the critical point were approximately at $500 \mathrm{~ms}$ after the stimulus onset (see also Leinonen et al., 2009). For the ERPs time-locked to the critical point, the mean amplitudes were calculated in the $80-120,170-210$, and $190-230 \mathrm{~ms}$ time windows. The 190-230 ms time-window was selected based on visual inspection of the critical point time-locked ERP data. This time-window is likely to correspond to the stimulus onset time-locked 700-780 time-window. The other two time windows (80-120 and 170-210 ms) were chosen in order to compare the ERP results with those of the ECD strengths. Repeated measures ANOVA were conducted on 12 lateral EEG electrodes (F7, F3, F4, F8, T7, C3, C4, T8, P7, P3, P4, P8). The electrodes were divided into three regions of interest (ROI):

${ }^{2}$ It should be noted that the RTs are rather suggestive, since the participants were explicitly instructed to judge the words as acceptable/unacceptable as accurately as possible, but not as quickly as possible. 
anterior (F3, F4), central (C3, C4), and posterior (P3, P4). To test hemispheric differences, the electrodes were divided into four ROIs: left (F7, T7, P7), left midline (F3, C3, P3), right midline (F4, C4, P4), and right (F8, T8, P8). For each time window of interest, the mean amplitudes were analyzed with three-way ANOVA with within-subject factors Condition (three levels: monomorphemic, derived, inflected), Anterior-Posterior Axis (anterior, central, posterior), and Laterality (left midline, left, right midline, right). Additionally, we conducted analyses for the midline electrodes with two within-subject factors: Condition (monomorphemic, derived, inflected) and Site ( $\mathrm{Fz}, \mathrm{Cz}, \mathrm{Pz})$. Post hoc tests were performed using the LSD test. All $p$-values were Greenhouse-Geisser corrected for non-sphericity when appropriate.

\section{MEG data}

The differences between conditions in dipole strength were assessed in the 80-120, 170-210, and 190-230 ms time windows. The 190-230 ms time-window was selected in order to compare the source strength results with the ERP results. The mean source amplitudes in each time window and hemisphere were assessed using separate repeated measures ANOVAs with factor Condition (monomorphemic, derived, inflected). Additionally, the distances between dipole locations for inflected vs. derived words, derived vs. monomorphemic words, as well as inflected vs. monomorphemic words in each hemisphere were tested against the baseline of $0 \mathrm{~mm}$ using the paired-samples $t$-test. In order to address the possibility of accepting false positives, the $p$-values were Bonferroni corrected.

\section{RESULTS}

\section{BEHAVIORAL RESULTS}

The mean error rates in the monomorphemic word condition were $2.8 \%(\mathrm{SD}=2)$, whereas in the derived word and inflected word conditions they were $4.1 \%(\mathrm{SD}=2.8)$ and $6.23 \%(\mathrm{SD}=3.1)$, respectively. The main effect of Condition was significant $[F(2,18)=9.69$, $p=0.001]$. Post hoc tests showed that inflected words elicited significantly more errors than monomorphemic words $(p=0.002)$ and derived words $(p=0.040)$. The difference in error rates between derived and monomorphemic words did not reach significance $(p=0.093)$. The mean RTs measured from the critical point were $671 \mathrm{~ms}(\mathrm{SD}=176), 769 \mathrm{~ms}(\mathrm{SD}=168)$, and $729 \mathrm{~ms}(\mathrm{SD}=190)$ for the monomorphemic, inflected, and derived words, respectively. There was a significant main effect of Condition $[F(2,18)=15.03$, $p=0.002]$. According to post hoc tests, inflected words elicited longer RTs than monomorphemic words $(p=0.001)$, and derived words elicited longer RTs than monomorphemic words $(p<0.001)$. There were no differences between inflected and derived words in the RTs measured from the critical point $(p=0.106)$.

\section{ERP RESULTS}

Figures 2 and 3 illustrate the grand average ERPs and topographic scalp maps for monomorphemic, inflected, and derived words time-locked to the stimulus onset or to the critical point. Inflected words elicited a larger negativity ${ }^{3}$ than monomorphemic and

${ }^{3}$ Although the absolute amplitude values may be positive, the difference between the ERP responses is negative. Additionally, the positive absolute values in this case are due to the baseline selection (i.e., prior to the critical point).

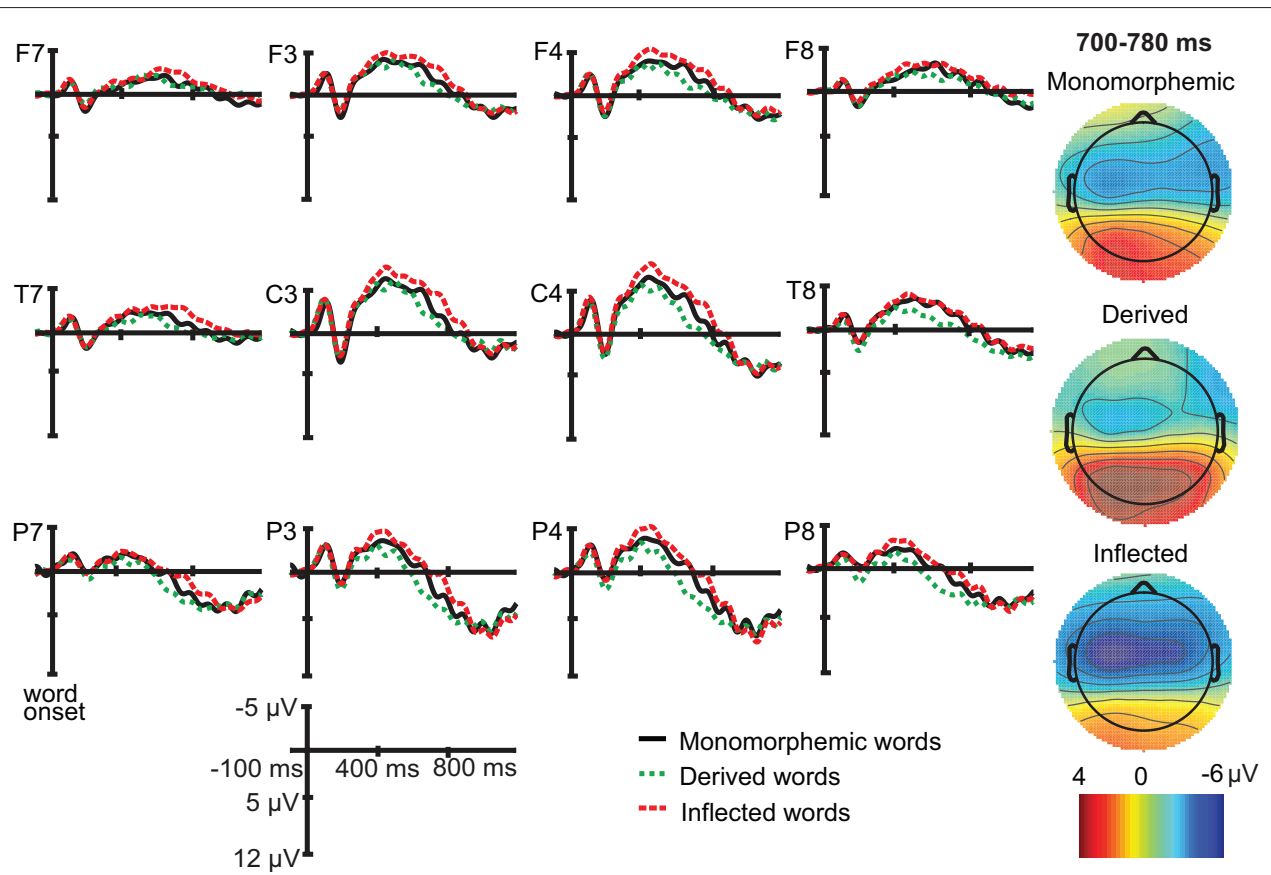

FIGURE 2 | (Left) grand average ERPs from 12 lateral scalp sites (F7, F3, F4 $\mathrm{F} 8, \mathrm{T7}, \mathrm{C} 3, \mathrm{C4}, \mathrm{T} 8, \mathrm{P7}, \mathrm{P3}, \mathrm{P4}, \mathrm{P8}$ ) to monomorphemic words (black solid line), derived words (green dotted line), and inflected words (red dashed line). Baseline is corrected in the $-100-0$ ms prestimulus interval. Time 0 is the onset of the stimuli. Negative polarity is plotted upwards. $X$-axis represents time (milliseconds), $Y$-axis depicts voltage (microvolts, $\mu \mathrm{V}$ ). (Right) topographic maps of the distribution of the negativity in the 700-780 ms time windows after stimulus onset for monomorphemic, derived, and inflected words. 

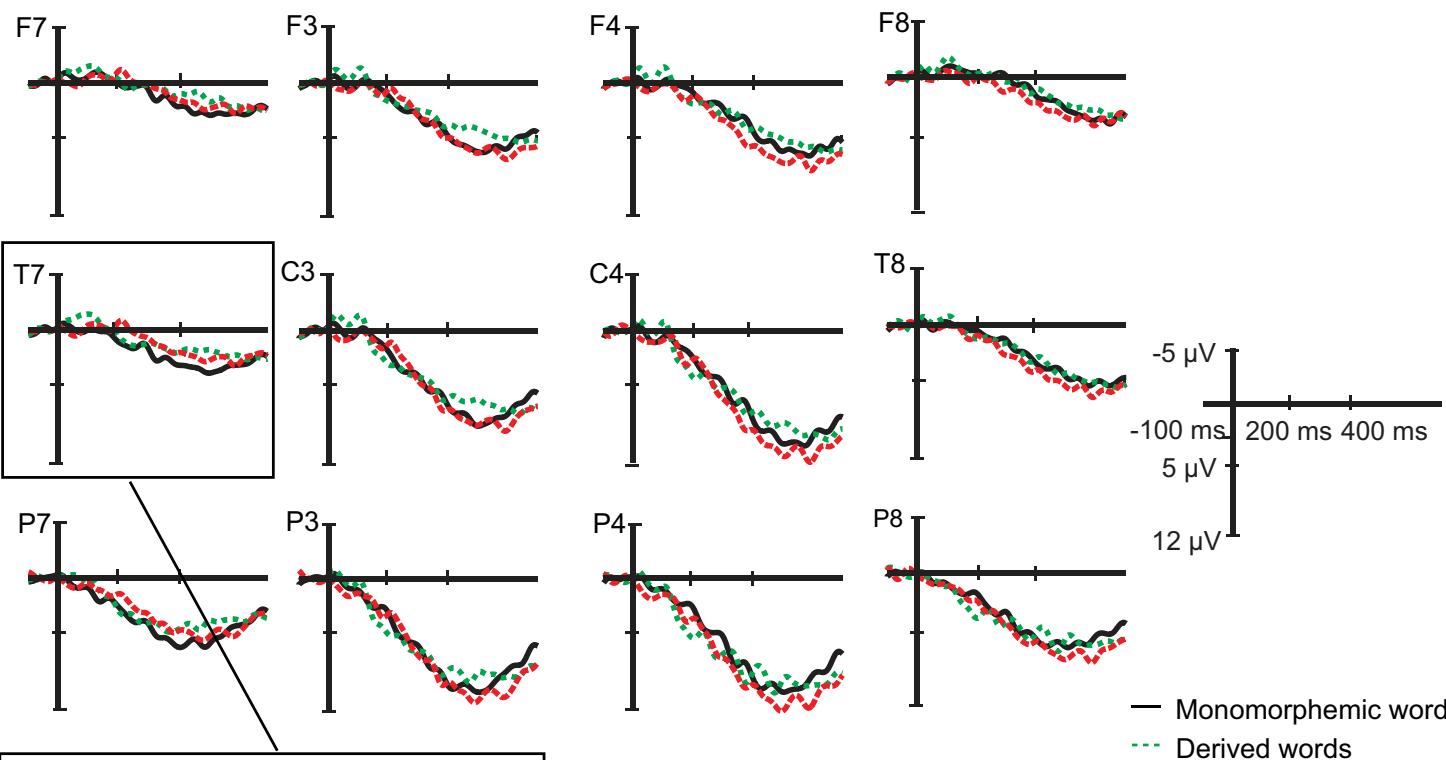

- Monomorphemic words

-.- Derived words



--- Inflected words

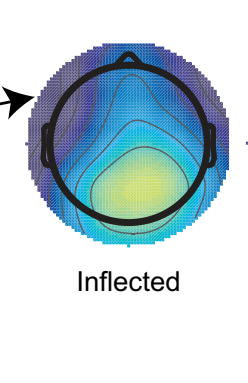

$190-230 \mathrm{~ms}$

A

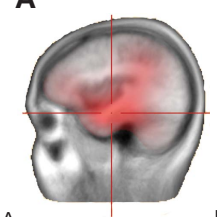

Monomorphemic word
B

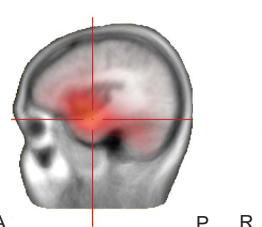

Derived word

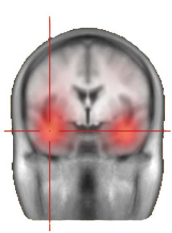

L A
C

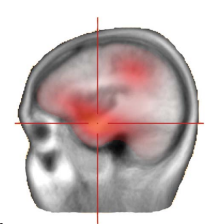



Monomorphemic

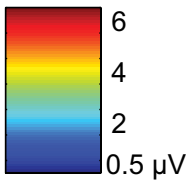

3002001000 $\mathrm{nAm} / \mathrm{cm}^{3}\left[\times 10^{-3}\right]$

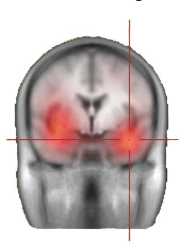

Inflected word

FIGURE 3 | (Above) grand average ERPs from 12 lateral scalp sites (F7, F3, F4, F8, T7, C3, C4, T8, P7, P3, P4, P8) to monomorphemic words (black solid line), derived words (green dotted line), and inflected words (red dashed line), with baseline correction in the $-100-0 \mathrm{~ms}$ time window before the critical point (i.e., uniqueness point for monomorphemic words; suffix onset for affixed words). Time 0 is the onset of the critical point. Negative polarity is plotted upwards. $X$-axis represents time (milliseconds), $Y$-axis depicts voltage (microvolts, $\mu \mathrm{V}$ ). (Middle; left) grand average ERPs from electrode T7. The time-window corresponding to that presented in the topographic maps is shadowed. (Middle; right) topographic maps of the distribution of the negativity in the 190-230 ms time-window after the critical point for the monomorphemic, derived, and inflected words. (Below) LORETA images for grand average ERP responses in the 190-230 ms time-window after the critical point for (A) monomorphemic, (B) derived, and (C) inflected words. derived words starting from $\sim 190 \mathrm{~ms}$ after the critical point (Figure 3). The LORETA analysis on ERP data in the 190-230 ms after the critical point revealed activation in the temporal areas in all conditions. Inflected and monomorphemic words showed maximal activity in the left temporal areas, whereas derived words showed maximal activity in the right hemisphere (Figure 3).

\section{ERPs time-locked to the stimulus onset}

In the 700-780 ms time window after the stimulus onset, the mean amplitudes at the lateral electrodes differed between the conditions [main effect for Condition: $F(2,18)=5.64, p=0.013$ ]. Post hoc tests showed that the magnitude of the negativity was larger for inflected words than for monomorphemic words $(p=0.033)$ and for derived words $(p=0.030)$. The negativity did not differ in magnitude 
between derived and monomorphemic words $(p=0.122)$. There was a significant interaction of Condition and Anterior-Posterior Axis $[F(4,36)=4.14, p=0.024]$ but not of Condition and Laterality $[F(6,54)=1.73, p=0.201]$. Post hoc tests showed that the differences in the negativity magnitude between the conditions were significant at central electrodes (inflected vs. monomorphemic: $p=0.011$; inflected vs. derived: $p=0.029)$. At the midline electrodes, the main effect for Condition was significant $[F(2,18)=4.95, p=0.04]$. Post hoc tests again showed that the negativity was larger for inflected words than for monomorphemic words $(p=0.041)$ and for derived words $(p=0.043)$. The interaction of Condition and Site was, however, not significant $[F(4,36)=1.84, p=0.142]$.

\section{ERPs time-locked to the critical point}

In the 190-230 ms time-window, at the lateral electrodes, there was no significant main effect for Condition $[F(2,18)=1.39, p=0.275]$. However, there was a significant interaction between Condition and Anterior-Posterior Axis $[F(4,36)=4.37, p=0.027]$, as well as between Condition and Laterality $[F(6,54)=3.2, p=0.04]$. Post hoc tests confirmed that inflected words elicited larger negativity than derived and monomorphemic words in the left hemisphere electrodes (inflected vs. derived: $p=0.038$; inflected vs. monomorphemic: $p=0.011$ ). There were no differences in the magnitude of the negativity between derived and monomorphemic words $(p=0.820)$. At the midline electrodes, the main effect of Condition was not significant $[F(2,18)=1.94, p=0.173]$, whereas the interaction Condition and Site reached significance $[F(4,36)=3.3$, $p=0.042]$. Post hoc tests did not, however, reveal any significant differences between the conditions at any electrode site.

The mean amplitude differences were also assessed in the same time windows as those in the ECD source modeling. In the $80-120 \mathrm{~ms}$ time-window after the critical point, at the lateral electrodes the main effect for Condition was non-significant $[F(2,18)=3.13, p=0.068]$. No significant interactions were observed (all $F<1.6$ ). At the midline electrodes, neither the main effect of Condition $(F<2)$ nor the Condition and Site interaction reach significance $(F<1)$. In the 170-210 ms time-window, the main effect of Condition was not significant $(F<2)$, however, both Condition and Anterior-Posterior Axis as well as Condition and Laterality were significant $\{[F(4,36)=4.18, p=0.038]$ and $[F(6,54)=4.44, p=0.016]$, respectively $\}$. Post hoc tests showed that derived words elicited smaller negativity than monomorphemic words at the posterior right midline electrode $\mathrm{P} 4(p=0.025)$. At the midline electrodes, the main effect of Condition was significant $[F(2,18)=3.91, p=0.039]$, and so was the Condition and Site interaction $[F(4,36)=3.8, p=0.011]$, with derived words showing a smaller negativity than monomorphemic words at all electrode sites (all $p<0.05)$.

\section{MEG RESULTS}

Figure 4 demonstrates the grand average MCE. The MCE shows that the processing of morphologically complex and simple words activates superior and middle temporal areas, more prominently in the left hemisphere. Figure 5 displays individual source locations (black dipoles), mean locations (red dipoles), and grand average (10 subjects) locations (green dipoles) as well as mean ED between conditions for Source pattern 1 and 2. The ECD activation is in

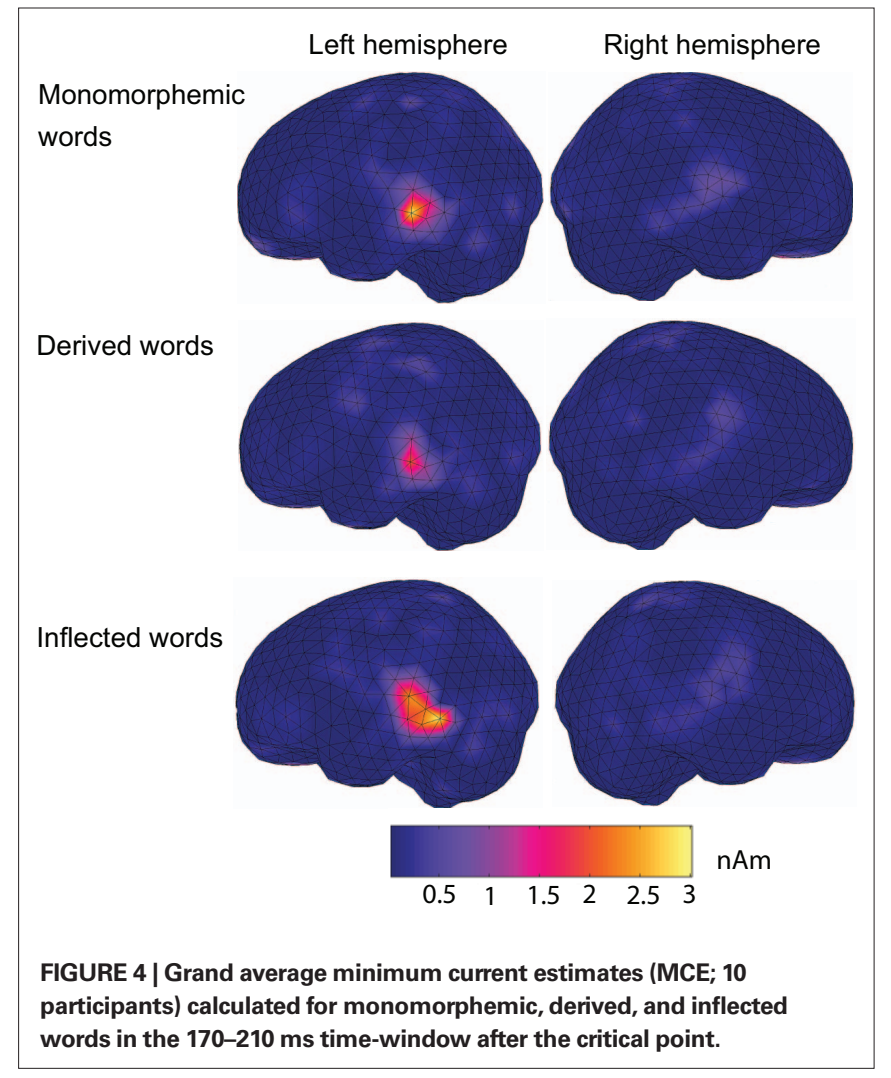

agreement with that detected using MCE and confirms the dominance of the superior/middle temporal cortices. Figure $\mathbf{6}$ shows the mean source waveforms and source amplitudes for all conditions and time windows of interest for Source patterns 1 and 2.

\section{Dipole strength}

In the 80-120 ms time window, the main effect of Condition was significant in the right but not in the left hemisphere $\{[F(2,14)=5.4, p=0.018] ;[F(2,14)=2.8, p=0.095]$, respectively $\}$. Post hoc tests showed that in the right hemisphere, the source amplitudes were larger for derived words than for monomorphemic and inflected words ( $p=0.004$ and $p=0.036$, respectively). There were no differences in the source strength of Source pattern 1 between inflected and monomorphemic words $(p=0.690)$. There were no significant differences between the conditions in the $170-210$ or $190-230 \mathrm{~ms}$ time windows in either hemisphere.

For Source pattern 2, in the 170-210 ms time-window, the main effect of Condition was significant in the left hemisphere $[F(2,12)=3.9, p=0.049]$. According to post hoc tests, inflected words had larger source amplitudes than derived words $(p=0.038)$. There were no differences in the source amplitudes between monomorphemic and derived $(p=0.81)$ or monomorphemic and inflected words $(p=0.104)$. In the right hemisphere, the main effect of Condition was not significant $(F<1.5)$. In the 190-230 ms time-window, the main effect of Condition also was significant in the left hemisphere $[F(2,12)=3.95$, $p=0.048]$. Post hoc tests showed that inflected words had larger source amplitudes than derived words $(p=0.034)$. The differences between monomorphemic and inflected words 


\section{A $\quad$ Source pattern 1}

$\mathrm{LH}$
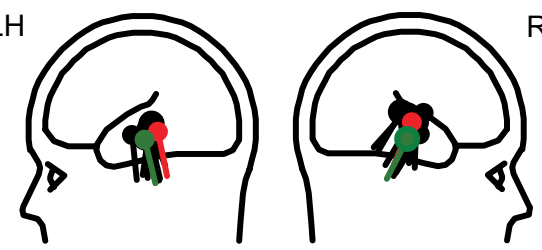

$\mathrm{RH}$


B

$\mathrm{LH}$

Monomorphemic words

Derived words

Mean

Euclidean

distance

Inflected words

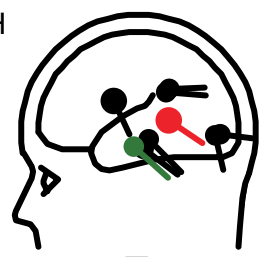
Source pattern 2

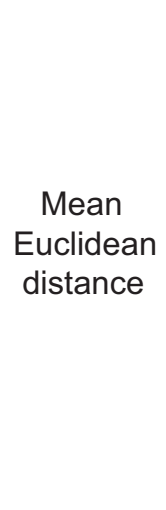

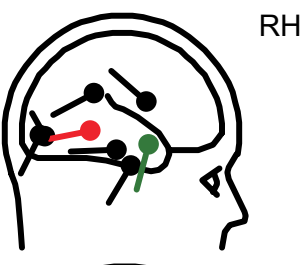
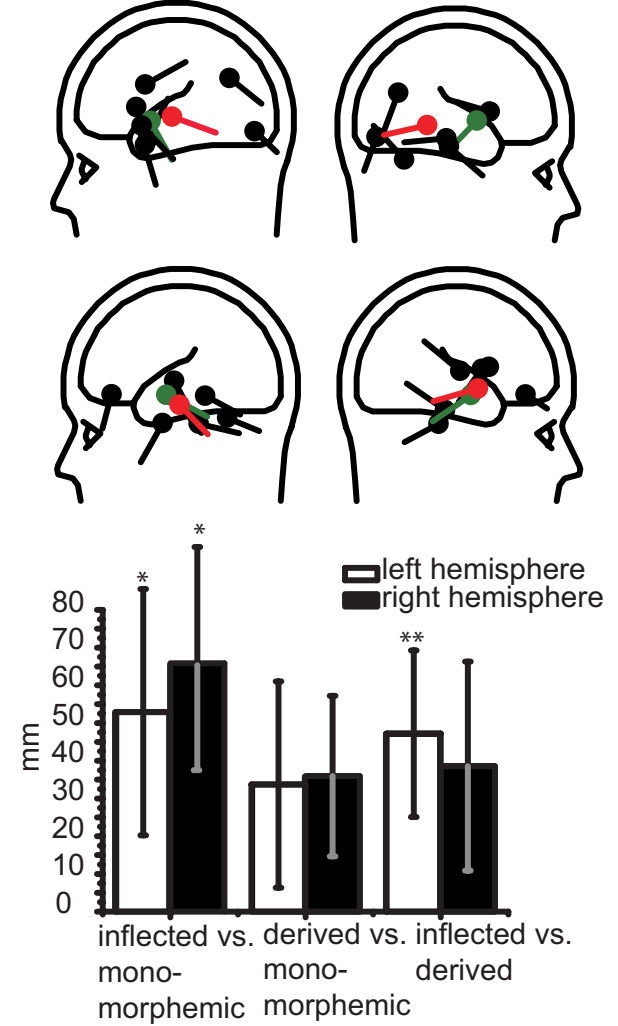

FIGURE 5 | (Above) individual dipole locations (black) for Source patterns 1 (80-120 ms after the critical point) and 2 (170-210 $\mathrm{ms}$ after the critical point) in the left and right hemisphere for monomorphemic, derived, and inflected words. Mean source locations and grand average (10 participants) locations are

displayed as red and green dipoles, respectively. (Below) mean Euclidean distance (columns) and SD (error bars) in millimeters between conditions for Source pattern 1 (A) and Source pattern 2 (B). Asterisks display significant differences between conditions against the baseline of $0 \mathrm{~mm}\left({ }^{* *}=p<0.01 ;{ }^{*}=p<0.05\right)$. or between monomorphemic and derived words were nonsignificant $[(p=0.087)$ and $(p=0.936)$, respectively $]$. In the right hemisphere, the main effect of Condition was not significant $[F(2,10)=2.67, p=0.118]$.

\section{Euclidean distance of dipole locations between conditions}

Figure 5 displays the mean ED values in millimeters between conditions for dipole positions in Source patterns 1 and 2 in each hemisphere. ED is sensitive to any differences in source locations and should demonstrate if modeled source locations vary between stimulus conditions. Pair-wise comparisons revealed that for Source pattern 1, in the left hemisphere, there were no significant differences in source locations between derived and inflected $[t(1,7)=2.38, p=0.294]$, between monomorphemic vs. derived, or monomorphemic vs. inflected words $\{[t(1,7)=1.95, p=0.092]$ and $[t(1,7)=1.7, p=0.133]$, respectively\}. However, in the right hemisphere, there were significant differences in dipole locations between inflected vs. derived $[t(1,7)=4.74, p=0.012]$, derived vs. monomorphemic $[t(1,7)=5.77, p=0.006]$, and inflected vs. monomorphemic words $[t(1,7)=4.58, p=0.018]$.

For Source pattern 2, in the left hemisphere, there were significant differences in dipole locations between inflected vs. derived $[t(1,6)=5.63, p=0.006]$ and between inflected vs. monomorphemic words $[t(1,6)=4.25, p=0.03]$ but not between monomorphemic vs. derived words $[t(1,6)=3.28, p=0.102]$. In the right hemisphere, there were significant differences in dipole locations between inflected vs. monomorphemic $[t(1,5)=4.68, p=0.03]$ but no differences between inflected vs. derived $[t(1,5)=3.41$, $p=0.057$ ] or between derived vs. monomorphemic words $[t(1,5)=4.14, p=0.054]$. 

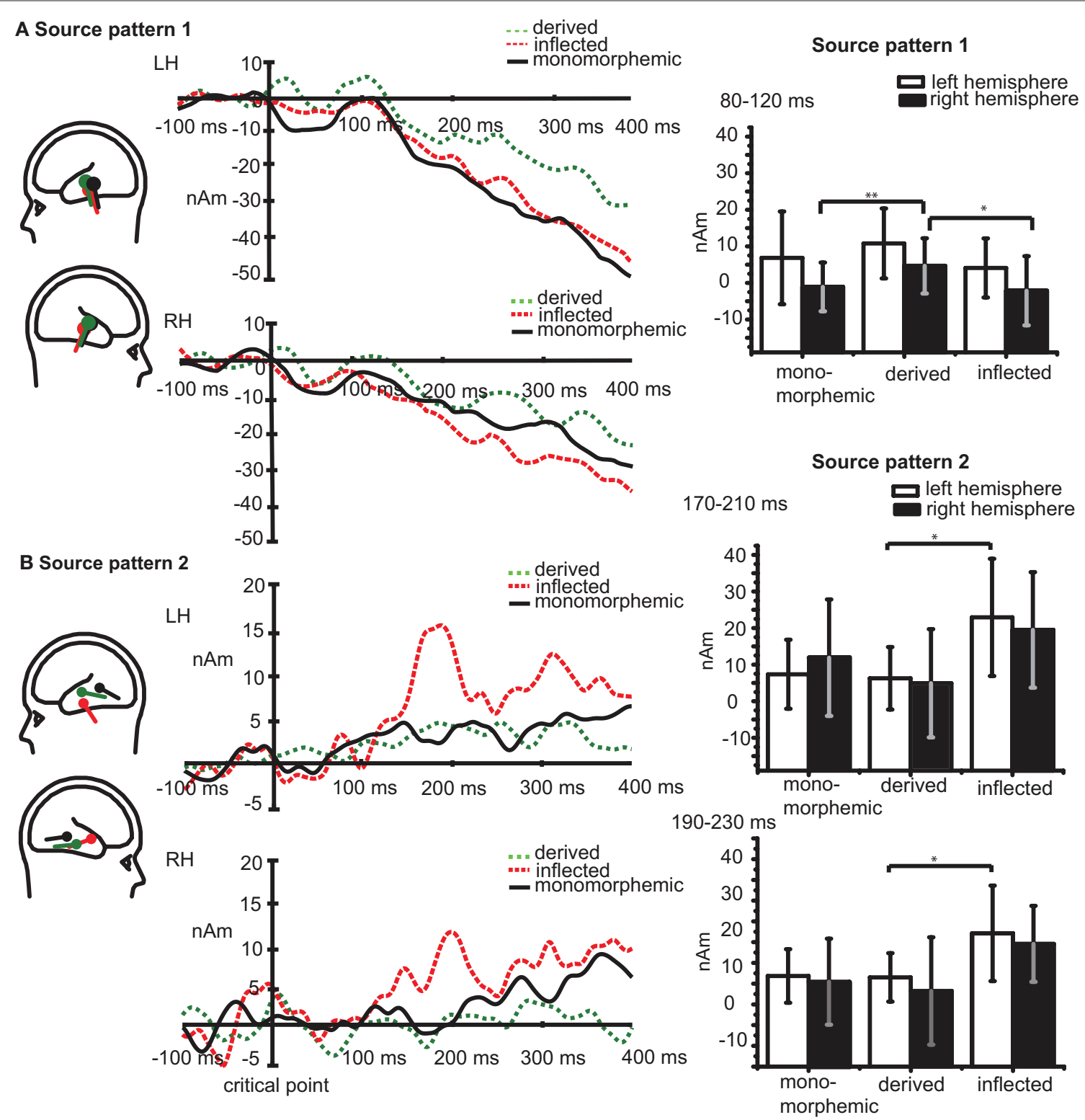

FIGURE 6 | (Left) mean source waveforms for Source patterns 1 (above) and 2 (below) in the left and right hemisphere for monomorphemic, derived, and inflected words. (Right) mean source amplitudes (columns) and SD (error bars) for monomorphemic, derived, and inflected words for Source pattern 1 (A) and Source pattern 2 (B). Asterisks display the alpha level $\left({ }^{*}=p<0.05\right)$. Mean dipole locations for inflected, derived, and monomorphemic words in the left and right hemispheres are depicted as red, green, and black dipoles, respectively.

\section{DISCUSSION}

The aim of the present study was to examine the spatiotemporal dynamics of morphological processing of spoken inflected and derived words. We also investigated whether the processing of derived words differs from that of inflected words in the auditory modality, particularly if the temporal unfolding of a complex word gives a head-start for accessing the stem and suffix separately even in derived words.

Our behavioral results demonstrated that there were more errors in the inflected word condition as compared to other conditions, whereas no differences were observed between derived and mono- morphemic words. The RT data measured from the critical point showed that inflected and derived words elicited longer RTs than monomorphemic words, whereas no differences were observed between derived and inflected words. However, our electrophysiological findings showed that inflected and derived words elicited distinct ERP responses in the auditory modality. Generally, our ERP findings are in line with those of Leinonen et al. (2008), who reported distinct responses for visually presented derived and inflected stimuli embedded in sentence contexts. Our MEG data showed that $\sim 100 \mathrm{~ms}$ after the critical point, all conditions produced similar magnetic field patterns, which were localized to the 
superior temporal area. In the right hemisphere, derived words showed larger source amplitudes than inflected and monomorphemic words. The MEG data further showed that $200 \mathrm{~ms}$ after the critical point, inflected words elicited larger source amplitudes than derived words in the left temporal area.

In the ERP data, importantly, both the stimulus onset and the critical point time-locked responses showed that inflected words elicited a larger negativity than monomorphemic and derived words. The observed larger negativity in contrast to monomorphemic words is in line with previous ERP and MEG studies on written (Lehtonen et al., 2007; Leinonen et al., 2009; Vartiainen et al., 2009a) and spoken (Leinonen et al., 2009) correctly inflected single words. Specifically, studies using visual stimuli have observed larger N400/N400m responses for written inflected than monomorphemic words (Lehtonen et al., 2007; Leinonen et al., 2009; Vartiainen et al., 2009a). Likewise, in the auditory modality, inflected words have elicited a larger N400 approximately at the time of suffix presentation (Leinonen et al., 2009). Worth noticing, however, is that the negativity observed in our study was left-lateralized when timelocked to the critical point (190-230 ms) and not lateralized when time-locked to stimulus onset. Although more temporally distributed (most prominently at F7 and T7), the larger left-lateralized negativity resembled LAN rather than N400 (see, e.g., RodriguezFornells et al., 2001, for morphology-related LAN with a more temporal distribution). The LORETA analysis of the grand average ERP data revealed that the source of this activity was located in the temporal area of the cortex. In MEG, the amplitudes for inflected words in Source pattern 2 were largest approximately $200 \mathrm{~ms}$ after the critical point (see below), suggesting that this source might be the primary generator of this left-lateralized negativity. The reason for the absence of the left-lateralized negativity in the stimulus onset time-locked data may be due to jitter in the suffix onset. The method of time-locking the responses to the critical point seems to abolish this problem, revealing more clearly the processes related to the processing of morphological endings.

Source localization of the processing of inflected and derived words revealed activation of two bilateral sources in the temporal area $\sim 200 \mathrm{~ms}$ after the critical point. The activation of the superior temporal cortex (Source pattern 1) is in line with the previous MEG studies using spoken and written morphologically complex stimuli (Bölte et al., 2009b; Pulvermüller and Shtyrov, 2009; Vartiainen et al., 2009a) as well as meaningful auditory stimuli per se (Helenius et al., 2002; Shtyrov et al., 2003; Uusvuori et al., 2008; Pulvermüller and Shtyrov, 2009; Pulvermüller et al., 2009; Vartiainen et al., 2009b). In general, the left superior temporal cortex has been suggested to be involved in the lexical access of words (Indefrey and Cutler, 2004), syntactic-semantic processing (Hagoort, 2005), and the mapping of speech input onto stored word meaning representations (Tyler et al., 2005). In our study, for the superior temporal source (Source pattern 1), there is remarkable systematicity in individual dipole locations in all conditions in the left hemisphere, suggesting that this source may reflect a process common to both inflected and derived words. This source activity may reflect access to the phonological and semantic features of incoming speech, possibly in an interactive manner. An important finding was the observed activity of Source pattern 2, where the magnetic field pattern was modeled by two separate sources. In
Source pattern 2 , in the left hemisphere, inflected words produced a short-lived and pronounced source effect, which was larger in amplitude as compared to derived words. There were also differences in source locations between inflected and derived as well as inflected and monomorphemic words in the left hemisphere. In general, the locations of individual sources for Source pattern 2 were more systematic in the inflected word condition, whereas monomorphemic and derived words showed a larger variability in individual source locations. The clear temporally and spatially distinct activity in Source pattern 2 may reflect a process specific to the processing of inflected words.

As described above, ECD modeling of the critical point timelocked MEG data showed that the effects localized systematically only in the inflected word condition, suggesting that this process was smaller or not present in the derived word condition. Moreover, at $\sim 200 \mathrm{~ms}$ after the critical point, the ERP responses were different for inflected words than for derived words. These left-lateralized differences suggest morphological decomposition for inflected words but not necessarily for derived words. Recent masked (for reviews, see, e.g., Marslen-Wilson and Tyler, 2007; Rastle and Davis, 2008) and overt (e.g., Marslen-Wilson et al., 1994) priming studies have proposed decompositional processing also for derived words. Yet, the current results are not in contrast with these findings, as priming has been used as an index of whether morphemic constituents have representations of their own that are activated during recognition. Even if derived words were primarily recognized via full-form representations, their morphemic constituents may also be simultaneously activated, as proposed by parallel dual-route models (e.g., Schreuder and Baayen, 1995). In our study, in Source pattern 1, there were differences in source amplitudes between the monomorphemic and derived words in the right hemisphere. This observation suggests that spoken derived words might also activate their morpheme representations in addition to full-form representations. This finding in the right hemisphere as well as the differences between derived and inflected words in the left hemisphere are in line with the recent fMRI study by Bozic et al. (2009). They found that derivational affixes in English do not selectively activate left-lateralized fronto-temporal areas as compared to inflected words, suggesting that derivational affixes may not trigger decompositional processes in the same way as inflectional affixes (Bozic et al., 2009). Most Finnish derived words are presented in the inflected form during natural speech (Vannest et al., 2002). This frequent double or triple affixation in Finnish might excessively tax morphological parsing processes and it would be more efficient to store the derived words in their full form (Vannest et al., 2002). Most derivational suffixes also contain allomorph variants, in contrast to more allomorph-invariant inflectional suffixes (Järvikivi et al., 2006). Hence, the general non-saliency of the suffixes might decrease their morphological transparency, possibly hindering the use of morphological parsing route of these forms (Järvikivi et al., 2006). This may explain the larger amplitudes of Source pattern 1 for derived words: as the unfolding of the stimulus still continued, the increased source magnitude may reflect the activation of the cohort candidates of allomorph variants of a derivational suffix (e.g., "aisti + kAs"/tasteful/ $\rightarrow$ aisti + kkAA + n/tasteful + GEN/). Larger dipolar strength might reflect a greater number of activated suffix allomorphs. 
Inflected words elicited a left-lateralized negativity and showed systematic activity in the superior and middle/inferior temporal cortices as revealed in the EEG and MEG source modeling. A few MEG studies have reported activation of superior temporal areas (Kubota et al., 2003; Service et al., 2007) as well as of inferior frontal and anterior temporal regions (Gross et al., 1998a; Friederici et al., 2000) in association with the left-lateralized negativity. In ERP studies on morphological processing, the LAN has been suggested to reflect combinatorial morphological structure building (Penke et al., 1997; Rodriguez-Fornells et al., 2001; Morris and Holcomb, 2005). The currently observed left-lateralized negativity for inflected words might reflect access to the grammatical features of an inflectional suffix and verification of the syntactic combinability of morpheme combination. Furthermore, as we used single inflected words without embedding them into sentence context, the activation of the Source pattern 2 may reflect the building of morphosyntactic context in order to form a correct meaning of the morpheme combination. Thus, the present evidence supports the assumption that Finnish inflected words are decomposed during recognition. The neural source activity might reflect the process of (morpho)syntactic licensing of the morpheme combination.

It should be noted that the fMRI studies on inflection have reported activation of the LIFG in addition to the temporal cortices (e.g., Laine et al., 1999; Tyler et al., 2005; Lehtonen et al., 2006), whereas several MEG studies on the processing of spoken and written meaningful words have observed activation only in temporal areas (e.g., Helenius et al., 2002; Shtyrov et al., 2003; Service et al., 2007; Uusvuori et al., 2008; Pulvermüller and Shtyrov, 2009; Pulvermüller et al., 2009; Vartiainen et al., 2009b). In fact, a recent study directly contrasted the neural activation patterns revealed by $\mathrm{fMRI}$ and MEG during reading, and found weaker frontal but stronger temporal effects in MEG than fMRI (Vartiainen et al., 2011). In accordance with these MEG findings, we did not observe consistent activation in the inferior frontal area in any stimulus condition in either MEG or EEG source modeling. As only a few MEG studies on (early) left-lateralized negativities have observed left frontal sources in addition to the temporal areas (Gross et al., 1998a; Knoesche et al., 1999; Friederici et al., 2000), it is possible that the anterior sources are poorly detectable with MEG due to their spatial orientation (Shtyrov et al., 2003), or the neural structures might not generate a clear dipolar field. Further studies are needed to investigate this issue in more detail also during audition.

In general, we found that inflected and derived words elicited distinct patterns of brain responses. Although we had a small sample size especially in the ECD modeling and the reliability of the results should be tested in the future studies, the findings were nevertheless significant and thus, robust. A further step would also be to address the issue of whether the differences between these word types are due to the word formation type per se (i.e., in some way

\section{REFERENCES}

Allen, M., Badecker, W., and Osterhout, L. (2003). Morphological analysis in sentence processing: an ERP study. Lang. Cogn. Process. 18, 405-430.

Anderson, S. R. (1992). A-Morphous Morphology. Camridge, MA:MIT Press.

associated to their linguistic function; e.g., Clahsen et al., 2003), or to the fact that they typically differ on a number of other properties as well, for instance on semantic transparency, affix frequency, and affixal salience, to name a few.

Taken together, the present results are compatible with the dual-route models of morphological processing (Niemi et al., 1994; Schreuder and Baayen, 1995), and, in particular, with the assumption that Finnish derived and inflected words are typically processed differently during recognition (Niemi et al., 1994). Our findings suggest that the processing of a spoken complex word might take place as follows: after initial acoustic-to-phonological encoding, morpheme activation proceeds by mapping phonological information into stored meaningful representations. The information enabling the retrieval of inflectional or derivational suffix starts to temporally unfold only after the acoustic completion of the base morpheme. The access of a suffix is reflected in the activation of the superior temporal cortex $\sim 100 \mathrm{~ms}$ after the suffix onset. Thereafter, if the lexical representation for the base + suffix combination already exists (as we assume to be the case with derived words), the lexical representation is retrieved in its full form, although the morphemes may also be initially activated separately. If the full form is available, then there might be no need for further parsing of the morpheme combination. This is reflected in the smaller negativity and smaller activation of the left middle/inferior temporal cortex for the derived words as compared to inflected words ( $200 \mathrm{~ms}$ after the suffix onset). However, if there is no match for the full-form representation (as seems to be the case with inflected words), the base and suffix are analyzed separately, and (morpho)syntactic features of the morpheme combination are evaluated. This is reflected in the larger left-lateralized negativity for the inflected as compared to the derived words $200 \mathrm{~ms}$ after the suffix onset. This negativity is generated in the cortical networks of the temporal lobe.

In summary, the current results present evidence for at least partially distinct cortical processing of spoken inflected and derived words. Inflected words elicited a larger left-lateralized negativity than derived words approximately $200 \mathrm{~ms}$ after the critical point. This negativity was most likely generated by two sources in the temporal cortices. The processing of spoken inflected words involves morphological decomposition. For spoken derived words, the base and suffix representation is initially activated along with the fullform representation.

\section{ACKNOWLEDGMENTS}

The current study was funded by the Ella and Georg Ehrnrooth foundation, University of Helsinki (own research funds), the Finnish Cultural Foundation, the Academy of Finland (projects $131963,212819,128840,137511)$, and HUSLAB.

feature contingencies. Neuroimage 41, 1111-1119.

Bertram, R., Laine, M., and Karvinen, K. (1999). The interplay of word formation type, affixal homonymy, and productivity in lexical processing: evidence from a morphologically rich language. J. Psycholinguist. Res. 28, 213-226.

Bölte, J., Jansma, B. M., Zilverstrand, A., and Zwitserlood, P. (2009a). Derivational morphology approached with event-related potentials. Ment. Lex. 4, 336-353. 
Bölte, J., Schulz, C., and Dobel, C. (2009b). Processing of existing, synonymous, and anomalous German derived adjectives: an MEG study. Neurosci. Lett. 469, 107-111.

Bozic, M., and Marslen-Wilson, W. D. (2010). Neurocognitive context for morphological complexity: dissociating inflection, and derivation. Lang. Linguist. Compass 4, 1063-1073.

Bozic, M., Marslen-Wilson, W. D., Stamatakis, E. A., Davis, M. H., and Tyler, L. K. (2007). Differentiating morphology, form, and meaning: neural correlates of morphological complexity. J. Cogn. Neurosci. 19, 1464-1475.

Bozic, M., Tyler, L. K., and MarslenWilson, W.D. (2009). Neuro-cognitive complexity of derivationally complex. J. Cogn. Neurosci. 21, SS1. [Supplement].

Butterworth, B. (1983). "Lexical representation," in Language Production, ed. B. Butterworth (London: Academic Press), 257-259.

Bybee, J. L. (1985). Morphology: A Study of the Relation Between Meaning and Form. Amsterdam: John Benjamins.

Caramazza, A., Laudanna, A., and Romani, C. (1988). Lexical access and inflectional morphology. Cognition 28, 297-332.

Clahsen, H., Sonnenstuhl, I., and Blevins, J.P. (2003). “Derivational morphology in the German mental lexicon: a dual mechanism account," in Morphological Structure in Language Processing, eds R. H. Baayen and R. Schreuder (Berlin: Mouton de Gruyter), 125-155.

Frauenfelder, U. H., and Schreuder, R. (1992). "Constraining psycholinguistic models of morphological processing and representation: the role of productivity," in Yearbook of Morphology 1991, eds G. E. Booij and J. van Marle (Dordrecht: Kluwer), 165-183.

Friederici, A. D., Wang, Y., Herrmann, C. S., Maess, B., and Oertel, U. (2000). Localization of early syntactic processes in frontal and temporal cortical areas: a magnetoencephalographic study. Hum. Brain Mapp. 11, 1-11.

Gold, B. T., and Rastle, K. (2007). Neural correlates of morphological decomposition during visual word recognition. J. Cogn. Neurosci. 19, 1983-1993.

Gross, J., Joannides, A. A., Dammers, J., Maess, B., Friederici,A.D., and MüllerGärtner,H.-W.(1998a). Magnetic field tomography analysis of continuous speech. Brain Topogr. 10, 193-204.

Gross, M., Say, T., Kleingers, M., Clahsen, H., and Münte, T. F. (1998b). Human brain potentials to violations in morphologically complex Italian words. Neurosci. Lett. 241, 83-86.
Hagoort, P. (2005). On Broca, brain, and binding: a new framework. Trends Cogn. Sci. (Regul. Ed.) 9, 416-423.

Hakulinen, A., Vilkuna, M., Korhonen, R., Koivisto, V., Heinonen, T. R., and Alho, I. (2004). Iso Suomen kielioppi. Helsinki: Suomalaisen Kirjallisuuden Seura.

Hansen, P. C., Kringelbach, M. L. and Salmelin, R. (2010). MEG: Introduction to Methods. NewYork: Oxford University Press.

Harris, J., Pylkkänen, L., McElree, B., and Frisson, S. (2008). The cost of question concealment: eye-tracking and MEG evidence. Brain Lang. 107, 44-61.

Helenius, P., Salmelin, R., Service, E., Connolly, J. F., Leinonen, S., and Lyytinen, H. (2002). Cortical activation during spoken-word segmentation in nonreading-impaired and dyslexic adults. J. Neurosci. 22, 2936-2944.

Hyönä, J., Laine, M., and Niemi, J. (1995). "Effects of a word's morphological complexity on readers' eye fixation patterns," in Eye Movement Research: Mechanisms, Processes and Applications, eds J. M. Findlay, R. W. Kentridge, and R. Walker (Amsterdam: North-Holland), 445-452.

Ille, N., Berg, P., and Scherg, M. (2002). Artifact correction of the ongoing EEG using spatial filters based on artifact and brain signal topographies. J. Clin. Neurophysiol. 19, 113-124.

Indefrey, P., and Cutler, A. (2004). "Prelexical and lexical processing in listening," in The Cognitive Neurosciences III, ed. M. S. Gazzaniga (Cambridge, MA: MIT Press), 759-774.

Janssen, U., Wiese, R., and Schlesewsky, M. (2006). Electrophysiological responses to violations of morphosyntactic and prosodic features in derived German nouns. J. Neurolinguistics 19, 466-482.

Järvikivi, J., Bertram, R., and Niemi, J. (2006). Affixal salience and the processing of derivational morphology: the role of suffix allomorphy. Lang. Cogn. Process. 21, 394-431.

Knoesche, T., Maess, B., and Friederici, A. D. (1999). Processing of syntactic information monitored by brain surface current density mapping based on MEG. Brain Topogr. 12, 75-87.

Krott, A., Baayen, R. H., and Hagoort, P. (2006). The nature of anterior negativities caused by misapplications of morphological rules. J. Cogn. Neurosci. $18,1616-1630$

Kubota, M., Ferrari, P., and Roberts, T. P. (2003). Magnetoencephalography detection of early syntactic processing in humans: comparison between L1 speakers and L2 learners of English. Neurosci. Lett. 353, 107-110.
Laine, M. (1996). Lexical status of inflectional and derivational suffixes: evidence from Finnish. Scand. J. Psychol. $37,238-248$.

Laine, M., Niemi, J., Koivuselkä-Sallinen, P., and Hyönä,J.(1995). Morphological processing of polymorphemic nouns in a highly inflecting language. $\operatorname{Cog} n$. Neuropsychol. 12, 457-502.

Laine, M., Rinne, J. O., Krause, B. J., Teräs, M., and Sipilä, H. (1999). Left hemisphere activation during processing of morphologically complex word forms in adults. Neurosci. Lett. 271, 85-88.

Lehtonen, M., Cunillera, T., RodríguezFornells, A., Hultén, A., Tuomainen, J., and Laine, M. (2007). Recognition of morphologically complex words in Finnish: evidence from eventrelated potentials. Brain Res. 1148 , 123-137.

Lehtonen, M., and Laine, M. (2003). How word frequency affects morphological processing in bilinguals and monolinguals. Biling. Lang. Cogn. 6, 213-225.

Lehtonen, M., Vorobyev, V. A., Hugdahl, K., Tuokkola, T., and Laine, M. (2006) Neural correlates of morphological decomposition in a morphologically rich language: an fMRI study. Brain Lang. 98, 182-193.

Leinonen, A., Brattico, P., Järvenpää, M. and Krause, C. M. (2008). Eventrelated potential (ERP) responses to violations of inflectional and derivational rules of Finnish. Brain Res. 1218 181-193.

Leinonen, A., Grönholm-Nyman, P., Järvenpää, M., Söderholm, C., Lappi, O., Laine, M., and Krause, C. M (2009). Neurocognitive processing of auditorily and visually presented inflected words and pseudowords: evidence from a morphologically rich language. Brain Res. 1275, 54-66.

Leminen, A., Leminen, M., and Krause, C. M. (2010). Time-course of the neural processing of spoken derived words: an ERP study. Neuroreport 21, 948-952.

Linares, R., Rodriguez-Fornells, A., and Clahsen, H. (2006). Stem allomorphy in the Spanish mental lexicon: evidence from behavioral and ERP experiments. Brain Lang. 97, 110-120.

Lück, M., Hahne, A., and Clahsen, H. (2006). Brain potentials to morphologically complex words during listening. Brain Res. 1077, 144-1452.

Marslen-Wilson, W. D., and Tyler, L. K. (2007). Morphology, language and the brain: the decompositional substrate for language comprehension. Philos. Trans. R. Soc. Lond. B Biol. Sci. 362 823-836.

Marslen-Wilson, W. D., Tyler, L. K. Waksler, R., and Older, L. (1994). Morphology and meaning in the
English mental lexicon. Psychol. Rev. 101, 3-33.

McQueen, J. M., and Cutler, A. (1998). "Morphology in word recognition," in Handbook of Morphology, eds A. Spencer and A. M. Zwicky (Oxford: Blackwell), 406-427.

Meinzer, M., Lahiri, A., Flaisch, T., Hannemann, R., and Eulitz, C. (2009). Opaque for the reader but transparent for the brain: neural signatures of morphological complexity. Neuropsychologia 47, 1964-1971.

Morris, J., and Holcomb, P. J. (2005). Event-related potentials to violations of inflectional verb morphology in English. Cogn. Brain Res. 25, 963-981.

Münte, T.F., Say, T., Clahsen, H., Schiltz, K., and Kutas, M. (1999). Decomposition of morphologically complex words in English: evidence from event-related brain potentials. Brain Res. Cogn. Brain Res. 7, 241-253.

Newman, A., Ullman, M., Pancheva, R., Waligura, D., and Neville, H. (2007). An ERP study of regular and irregular English past tense inflection. Neuroimage 34, 435-445.

Niemi, J., Laine, M., and Tuominen, J. (1994). Cognitive morphology in Finnish: foundations of a new model. Lang. Cogn. Process. 3, 423-446.

Palmovic, M., and Maricic, A. (2008). Mental lexicon and derivational rules. Coll. Antropol. 32(Suppl. 1), 177-181.

Penke, M., Weyerts, H., Gross, M., Zander, E., Münte, T., and Clahsen, H. (1997). How the brain processes complex words: an event-related potential study of German verb inflections. Brain Res. Cogn. Brain Res. 6, 37-52.

Perrin, F., Pernier, J., Bertrand, O., and Echallier,J. F. (1989). Spherical splines for scalp potential and current density mapping. Electroencephalogr. Clin. Neurophysiol. 72, 184-187.

Pinker, S. (1991). Rules of language. Science 253, 153-195.

Pulvermüller, F., and Shtyrov, Y. (2009). Spatiotemporal signatures of largescale synfire chains for speech processing as revealed by MEG. Cereb. Cortex $19,79-88$.

Pulvermüller, F., Shtyrov, Y., and Hauk, O. (2009). Understanding in an instant: neurophysiological evidence for mechanistic language circuits in the brain. Brain Lang. 110, 81-94.

Pylkkänen, L., Llinas, R., and Murphy, G. L. (2006). The representation of polysemy: MEG evidence. J. Cogn. Neurosci. 18, 1-13.

Rastle, K., and Davis, M. H. (2008). Morphological decomposition based on the analysis of orthography. Lang. Cogn. Process. 23, 942-971.

Rodriguez-Fornells, A., Clahsen, H., Lleó, C., Zaake, W., and Münte, T. F. (2001) 
Event-related brain responses to morphological violations in Catalan. Brain Res. Cogn. Brain Res. 11, 47-58.

Scalise, S. (1988). Inflection and derivation. Linguistics 26, 561-581.

Schreuder, R., and Baayen, R. H. (1995). "Modeling morphological processing," in Morphological Aspects of Language Processing, ed.L. B. Feldman (Hillsdale, NJ: Lawrence Erlbaum), 131-154.

Service, E., Helenius, P., Maury, S., and Salmelin, R. (2007). Localization of syntactic and semantic brain responses using magnetoencephalography. J. Cogn. Neurosci. 19, 1193-1205.

Shtyrov, Y., Pulvermüller, F., Näätänen, R., and Ilmoniemi, R. J. (2003). Grammar processing outside the focus of attention: an MEG study. J. Cogn. Neurosci. 15, 1195-1206.

Soveri, A., Lehtonen, M., and Laine, M. (2007). Word frequency and morphological processing in Finnish revisited. Ment. Lex. 2, 359-385.

Stockall, L., and Marantz,A. (2006). A single route, full decomposition model of morphological complexity: MEG evidence. Ment. Lex. 1, 85-123.

Stump, G. T. (1998). "Inflection," in The Handbook of Morphology, eds A. Spencer and A. M. Zwicky (Oxford: Blackwell), 13-43.
Taft, M. (1979). Recognition of affixed words and word frequency effect. Mem. Cognit. 7, 263-272.

Taft, M., and Forster, K. I. (1975). Lexical storage and retrieval of prefixed words. J. Verb. Learn. Verb. Behav. 14, 638-647.

Taulu, S., and Simola, J. (2006). Spatiotemporal signal space separation method for rejecting nearby interference in MEG measurements. Phys. Med. Biol. 51, 1759-1768.

Tyler, L. K., Stamatakis, E. A., Post, B., Randall, B., and Marslen-Wilson, W. (2005). Temporal and frontal systems in speech comprehension: an fMRI study of past tense processing. Neuropsychologia 43, 1963-1974.

Uusvuori, J., Parviainen, T., Inkinen, M., and Salmelin, R. (2008). Spatiotemporal interaction between sound form and meaning during spoken word perception. Cereb. Cortex 18 , 456-466.

Vannest, J., Bertram, R., Järvikivi, J., and Niemi, J. (2002). Counterintuitive cross-linguistic differences: more morphological computation in English than in Finnish. J. Psycholinguist. Res. 31, 83-106.

Vannest, J., Polk, T. A., and Lewis, R. L. (2005). Dual-route processing of com- plex words: new fMRI evidence from derivational suffixation. Cogn. Affect. Behav. Neurosci. 5, 67-76.

Vartiainen, J., Aggujaro, S., Lehtonen, M., Hulten, A., Laine, M., and Salmelin, R. (2009a). Neural dynamics of reading morphologically complex words. Neuroimage 47, 2064-2072.

Vartiainen, J., Parviainen, T., and Salmelin, R. (2009b). Spatiotemporal convergence of semantic processing in reading and speech perception. J. Neurosci. 29, 9271-9280.

Vartiainen, J., Liljeström, M., Koskinen, M., Renvall, H., and Salmelin, R. (2011). Functional magnetic resonance imaging blood oxygenation level-dependent signal and magnetoencephalography evoked responses yield different neural functionality in reading. J. Neurosci. 31, 1048-1058.

Virtanen, J., Rinne, T., Ilmoniemi, R. J., and Näätänen, R. (1996). MEGcompatible multichannel EEG electrode array. Electroencephalogr. Clin. Neurophysiol. 99, 568-570.

Weyerts, H., Penke, M., Dohrn, U., Clahsen, H., and Münte, T. F. (1997). Brain potentials indicate difference between regular and irregular German plurals. Neuroreport 8, 957-962.
Zweig,E., and Pylkkänen, L. (2008). A visual M170 effect of morphological complexity. Lang. Cogn. Process. 24, 412-439.

Conflict of Interest Statement: The authors declare that the research was conducted in the absence of any commercial or financial relationships that could be construed as a potential conflict of interest.

Received: 16 March 2011; paper pending published: 18 May 2011; accepted: 08 July 2011; published online: 21 July 2011.

Citation: Leminen A, Leminen M, Lehtonen $M$, Nevalainen $P$, Ylinen S, Kimppa L, Sannemann C, Mäkelä JP and Kujala T (2011) Spatiotemporal dynamics of the processing of spoken inflected and derived words: a combined EEG and MEG study. Front. Hum. Neurosci. 5:66. doi: 10.3389/ fnhum.2011.00066

Copyright (C) 2011 Leminen, Leminen, Lehtonen, Nevalainen, Ylinen, Kimppa, Sannemann, Mäkelä and Kujala. This is an open-access article subject to a nonexclusive license between the authors and Frontiers Media SA, which permits use, distribution and reproduction in other forums, provided the original authors and source are credited and other Frontiers conditions are complied with. 